\title{
Imunodeteç̧ão de Toxoplasma gondii em tecido placentário de cabras naturalmente infectadas
}

\author{
[Immunodetection of Toxoplasma gondii in placenta tissue of naturally infected goats] \\ E.P. Mesquita ${ }^{1}$, J.M.B. Oliveira ${ }^{1}$, G.M. Silva ${ }^{2}$, S.M. Torres ${ }^{2}$, A.A.F. Oliveira ${ }^{3}$, \\ V.A. Silva Júnior ${ }^{3}$, R.A. Mota ${ }^{3}$, M.J.A.A.L. Amorim ${ }^{3}$ \\ ${ }^{1}$ Aluno de pós-graduação - Universidade Federal Rural de Pernambuco - Recife, PE \\ ${ }^{2}$ Médica veterinária autônoma - Recife, PE \\ ${ }^{3}$ Universidade Federal Rural de Pernambuco - Recife, PE
}

\begin{abstract}
RESUMO
A imuno-histoquímica (IHQ) é considerada uma ferramenta rápida e precisa para a identificação de protozoários, como Toxoplasma gondii, em tecidos fetais e placentários. Neste estudo foi avaliada a imunodetecção de Toxoplasma gondii em tecido placentário de cabras naturalmente infectadas. Foram coletadas e analisadas 80 amostras de placentas de cabras procedentes de único rebanho com sorologia positiva para T. gondii na técnica de ELISA. Na histopatologia, 27/80 amostras apresentaram lesões sugestivas de infecção por protozoários. Após a avaliação histopatológica, procedeu-se à realização da técnica de imunohistoquímica, obtendo-se 85,2\% (23/27) de amostras com marcação positiva. A imunodetecção ocorreu no epitélio de revestimento das vilosidades coriônicas e foi classificada de acordo com o grau de intensidade da imunomarcação. Também foi evidenciada imunomarcação no interior dos vasos sanguíneos fetais em 8,69\% (2/23) das amostras. Este estudo demonstrou que a técnica de IHQ se comportou como uma ferramenta valiosa no diagnóstico da infeção por $T$. gondii em tecido placentário de cabras naturalmente infectadas e complementou, de forma decisiva, o diagnóstico, além de agregar maior valor aos resultados obtidos nas análises histopatológica e sorológica.
\end{abstract}

Palavras-chave: caprinos, placenta, toxoplasmose, imunodiagnóstico

\begin{abstract}
Immunohistochemistry (IHC) is considered to be a rapid and accurate tool for the identification of protozoa such as Toxoplasma gondii in fetal and placental tissues. In this study, we evaluated the immunodetection of Toxoplasma gondii in placental tissue from naturally infected goats. A total of 80 samples of goat placentas from a single herd with positive ELISA serology for T. gondii were collected and analyzed. In the histopathology, 27/80 samples presented lesions suggestive of protozoal infection. After the histopathological evaluation, the immunohistochemistry technique was performed, obtaining 85.2\% (23/27) of samples with positive marking. Immunodetection occurred in the lining epithelium of the chorionic villi and was classified according to the degree of intensity of the immunostaining. Immunostaining within the fetal blood vessels was also evidenced in $8.69 \%$ (2/23) of the samples. This study demonstrated that the IHQ technique behaved as a valuable tool in the diagnosis of $\mathrm{T}$. gondii infection in placental tissue of naturally infected goats completing the diagnosis in a decisive way and adding greater value to the results obtained in the histopathological and serological analysis.
\end{abstract}

Keywords: goats, placenta, toxoplamosis, immunodiagnosis

\section{INTRODUÇÃO}

Dentre as várias etiologias relacionadas a problemas reprodutivos em pequenos ruminantes, destaca-se a toxoplasmose causada por Toxoplasma gondii, protozoário pertencente ao filo Apicomplexa (Dubey, 2009). Trata-se de um protozoário intracelular obrigatório de distribuição mundial e de caráter zoonótico, que acomete os pequenos ruminantes e outros mamíferos (Massala et al., 2003). A doença também foi relatada como importante causa de prejuízos econômicos na caprinocultura (Munday e Mason, 1979). Os felídeos são considerados os

Recebido em 13 de junho de 2017

Aceito em 2 de julho de 2018

E-mail: polimeni.emanuela@gmail.com 
hospedeiros definitivos de $T$. gondii, e os oocistos liberados nas fezes desses animais infectam outras espécies animais por meio da transmissão horizontal. Nesta espécie, a transmissão vertical também pode ocorrer por via transplacentária (Dubey, 2010).

O sistema imune não elimina o $T$. gondii, que se aloja nos tecidos em forma de cistos, os quais podem persistir por vários anos no hospedeiro. Alguns desses cistos podem se romper em períodos de imunossupressão, liberando os bradizoítos, que posteriormente se modificam em taquizoítos (Dubey e Lindsay, 2006).

Toxoplasma gondii também pode comprometer o desenvolvimento do embrião, culminando em sua morte e interferindo na taxa de reabsorção embrionária de cabras (Wanderley et al., 2013). Além disso, esse protozoário pode causar morte fetal, mumificação, abortos (Buxton, 1998) e nascimento de crias debilitadas (Blewett e Watson, 1983).

As infecções por $T$. gondii vêm sendo relatadas em vários países do mundo, por meio do diagnóstico nos fetos abortados (Charleston, 1994), como na região da Múrcia/Espanha, em cabras e ovelhas (Navarro et al., 2009); em cabras (Caldeira et al., 2011; Pescador et al., 2007); na Jordânia, em cabras e ovelhas (AbuDalbouh et al., 2012); ovelhas, na Turquia (Atmaca et al., 2012); e, na Argentina, cabras (Ungaza et al., 2014).

Em um estudo retrospectivo sobre abortos na Califórnia, analisaram-se 211 casos em caprinos no período de 1991 a 1998 . O resultado mostrou que $30,5 \%$ foram de origem bacteriana; $2 \%$, viral; $0,5 \%$, fúngica; e $4 \%$ de origem protozoária. O diagnóstico dos abortos foi confirmado por meio da observação de taquizoítos nos tecidos por IHQ ou pela presença de anticorpos com títulos elevados para o protozoário na técnica de aglutinação em látex (Moeller, 2001).

São recomendados exames laboratoriais com base em técnicas de pesquisa de antígenos teciduais para a confirmação da causa dos abortos (Dubey, 2009), destacando-se a imunohistoquímica (IHQ), que apresenta bons resultados mesmo em animais com títulos baixos de anticorpos contra o agente (Dagleish et al., 2010; Silva et al., 2013).

Arq. Bras. Med. Vet. Zootec., v.71, n.1, p.86-92, 2019
Considerando-se a escassez de estudos direcionados ao diagnóstico das causas de abortos em cabras no Brasil e a ausência de um padrão de diagnóstico por imuno-histoquímica em tecido placentário de cabras, objetivou-se detectar T. gondii em tecido placentário de cabras naturalmente infectadas, pela técnica de imuno-histoquímica.

\section{MATERIAL E MÉTODOS}

O projeto foi submetido e aprovado pelo Comitê de Ética no Uso de Animais da Universidade Federal Rural de Pernambuco (Licença $n^{\circ}$ 122/2015).

O acompanhamento das cabras naturalmente infectadas por $T$. gondii foi realizado em uma propriedade no estado de Alagoas. As cabras que apresentaram histórico de surto recente de aborto eram criadas em sistema de manejo intensivo, alimentadas à base de silagem de milho ou capim-elefante e concentrado comercial para as gestantes e lactantes. A mineralização fornecida era comercial, e a água proveniente de poço artesiano.

Inicialmente, realizou-se um levantamento sorológico nas cabras deste rebanho, coletandose 246 amostras de soro analisadas pela técnica de ELISA, de acordo com o protocolo de Álvarez-García et al. (2003), para se confirmar a infecção por Toxoplasma gondii. Após a confirmação de positividade no rebanho para esse protozoário, seguiu-se o acompanhamento dos animais para coleta de amostras das placentas. Durante o parto foram coletadas amostras de 80 placentas que, inicialmente, foram submetidas ao método rotineiro de processamento e inclusão em parafina e, posteriormente, foram submetidas à análise histopatológica para identificação de lesões compatíveis com Toxoplasma gondii segundo critério estabelecido por Buxton e Finlayson (1986). As amostras placentárias foram analisadas quanto à presença de áreas de necrose, infiltrados mononucleares e áreas de calcificação e, posteriormente, foram submetidas à técnica de IHQ (Pereira-Bueno et al., 2004).

Para a realização da imuno-histoquímica, foram utilizados 27 fragmentos de placentas, sendo 22 com lesões compatíveis com toxoplasmose na histopatologia e cinco sem lesões, provenientes de animais com sorologia positiva. Os cortes 
foram realizados em micrótomo e dispostos em lâminas previamente silanizadas. Inicialmente, foi realizada desparafinização e recuperação antigênica pela imersão em solução ácido cítrico ( $\mathrm{pH} 6,0)$, bloqueio de peroxidase endógena com peróxido de hidrogênio a 30-32\% (30 volumes) e incubação com anticorpo anti-Toxoplasma gondii de caprino positivo, com diluição de 1:100. O bloqueio das reações inespecíficas foi realizado pela imersão em solução de leite desnatado a $6 \%$, diluído em tampão citrato. A IHQ foi realizada pela técnica de estreptavidina-biotina-peroxidase com o kit comercial (DAKO LSAB2 SystemHRP K0675, DAKO North America, USA). As lâminas foram contracoradas com hematoxilina de Harris, desidratadas e montadas com bálsamo do Canadá. Foram também utilizados como controles positivos e negativos fragmentos de placentas sabidamente positivas e negativas na IHQ para esse protozoário.

As imunomarcações foram classificadas de acordo com a intensidade das reações na IHQ, em discretas (+), moderadas (++) e severas $(+++)$, segundo metodologia descrita por Costa et al. (2014).

\section{RESULTADOS}

No rebanho estudado, observou-se frequência de $86,6 \%(213 / 246)$ de cabras positivas na sorologia. Das 80 amostras de placenta coletadas, 22 amostras $(27,5 \%)$ apresentaram lesões histopatológicas ou macroscópicas características de infecções por T. gondii.

As lesões macroscópicas nas placentas foram caracterizadas por áreas necróticas de coloração branco-amarelada nos cotilédones. $\mathrm{Na}$ análise histopatológica, observaram-se lesões características de infecções por protozoários como áreas focais de necrose, infiltrados inflamatórios mononucleares e áreas de calcificação focal.

$\mathrm{Na}$ análise por IHQ, das 27 amostras de placenta analisadas, $23 \quad(85,2 \%) \quad$ apresentaram imunomarcação positiva, confirmando, assim, a infecção por $T$. gondii. Os resultados obtidos na histopatologia e na IHQ estão apresentados na Tab. 1.

Das 80 amostras de placentas submetidas ao exame histopatológico, três foram provenientes de animais negativos na sorologia, que apresentaram lesões características de infecções por protozoários, e positivos na IHQ.

Tabela 1. Resultados das técnicas de ELISA, análise histopatológica e imuno-histoquímica e suas respectivas frequências absoluta e relativa

\begin{tabular}{|c|c|c|c|}
\hline Identificação & $\begin{array}{l}\text { ELISA } \\
\text { (soro) }\end{array}$ & $\begin{array}{c}\text { Análise } \\
\text { histopatológica } \\
\text { (placenta) }\end{array}$ & $\begin{array}{c}\text { IHQ } \\
\text { (placenta) }\end{array}$ \\
\hline Animal 1 & + & + & + \\
\hline Animal 2 & + & + & + \\
\hline Animal 3 & + & + & + \\
\hline Animal 4 & - & + & - \\
\hline Animal 5 & + & + & + \\
\hline Animal 6 & - & + & + \\
\hline Animal 7 & - & + & + \\
\hline Animal 8 & - & + & - \\
\hline Animal 9 & + & + & + \\
\hline Animal 10 & + & + & + \\
\hline Animal 11 & - & + & + \\
\hline Animal 12 & + & - & + \\
\hline Animal 13 & + & + & + \\
\hline Animal 14 & + & - & + \\
\hline Animal 15 & + & + & - \\
\hline Animal 16 & + & + & + \\
\hline Animal 17 & + & + & + \\
\hline Animal 18 & + & + & + \\
\hline Animal 19 & + & + & + \\
\hline Animal 20 & + & + & + \\
\hline Animal 21 & + & + & + \\
\hline Animal 22 & + & + & + \\
\hline Animal 23 & + & - & + \\
\hline Animal 24 & + & - & + \\
\hline Animal 25 & + & + & + \\
\hline Animal 26 & + & - & - \\
\hline Animal 27 & + & + & + \\
\hline $\begin{array}{l}\text { Frequência } \\
\text { absoluta }\end{array}$ & $22 / 27$ & $22 / 27$ & $23 / 27$ \\
\hline $\begin{array}{l}\text { Frequência } \\
\text { relativa }\end{array}$ & $81,5 \%$ & $81,5 \%$ & $85,2 \%$ \\
\hline
\end{tabular}

+: positivo; -: negativo.

As reações positivas observadas na IHQ localizaram-se principalmente no epitélio de revestimento das vilosidades coriônicas, o que indica a presença do agente nesse local (Fig. 1). 


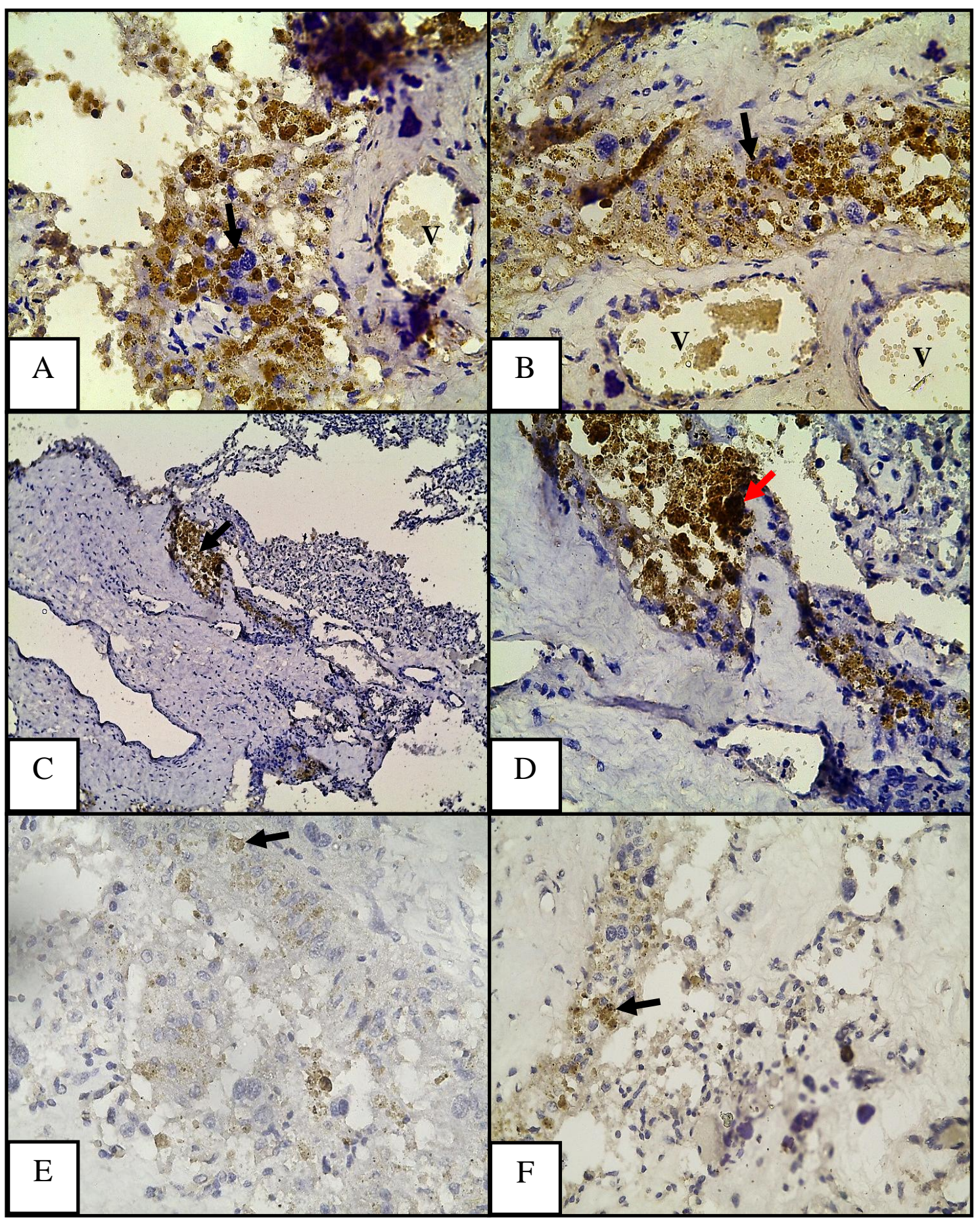

Figura 1. placentas de cabras naturalmente infectadas por T. gondii, analisadas na imuno-histoquímica. Figuras 1A e 1B: severa imunomarcação no interior de células trofoblásticas (seta) e vasos sanguíneos (V); hematoxilina de Harris (x400). Figura 1C: severa imunomarcação em epitélio de revestimento de vilosidade coriônica (seta); hematoxilina de Harris (x100). Figura 1D: área ampliada com visualização de células trofoblásticas com severa imunomarcação em citoplasma (seta vermelha); hematoxilina de Harris (x400). Figura 1E: discreta imunomarcação em citoplasma de trofoblastos (seta); hematoxilina de Harris (x400). Figura 1F: moderada imunomarcação em epitélio de revestimento da vilosidade coriônica; hematoxilina de Harris (x400). 
O epitélio de revestimento das vilosidades apresentou lesões com graus que variaram de reações moderadas a severas na imunohistoquímica, e uma amostra com imunomarcação discreta (Tab. 2). Foram visibilizadas células trofoblásticas vacuolizadas com imunomarcação positiva para $T$. gondii. Reação positiva no interior de vasos sanguíneos placentários foi evidenciada em 8,69\% (2/23), indicando a presença do parasito.

Tabela 2. Classificação das células imunorreativas em IHQ para T. gondii

\begin{tabular}{cc}
$\begin{array}{c}\text { Identificação da } \\
\text { amostra }\end{array}$ & $\begin{array}{c}\text { Intensidade de células } \\
\text { imunorreativas na IHQ }\end{array}$ \\
\hline Placenta 1 & +++ \\
Placenta 2 & +++ \\
Placenta 3 & +++ \\
Placenta 4 & - \\
Placenta 5 & ++ \\
Placenta 6 & ++ \\
Placenta 7 & +++ \\
Placenta 8 & - \\
Placenta 9 & +++ \\
Placenta 10 & +++ \\
Placenta 11 & +++ \\
Placenta 12 & ++ \\
Placenta 13 & ++ \\
Placenta 14 & +++ \\
Placenta 15 & - \\
Placenta 16 & +++ \\
Placenta 17 & + \\
Placenta 18 & ++ \\
Placenta 19 & +++ \\
Placenta 20 & +++ \\
Placenta 21 & ++ \\
Placenta 22 & ++ \\
Placenta 23 & ++ \\
Placenta 24 & ++ \\
Placenta 25 & +++ \\
Placenta 26 & - \\
Placenta 27 & +++ \\
\hline Craus e 1 s & ++ \\
\hline
\end{tabular}

Graus de lesões: discreta $(+)$, moderada $(++)$ e severa $(+++)$. Imuno-histoquímica classificada de acordo com a intensidade da imunomarcação das células (x400).

Das placentas com imunomarcação positiva, $4,4 \%(1 / 23)$ apresentaram reação discreta, $34,8 \%$ $(8 / 23)$ moderada e $60,8 \%(14 / 23)$ severa.

\section{DISCUSSÃO}

T. gondii é um importante agente envolvido em perdas reprodutivas na caprinocultura em diversas partes do mundo. Estudos realizados nos EUA (Moeller, 2001), no Brasil (Pescador et al.,
2007), na Jordânia (Abu-Dalbouh et al., 2012) e na Argentina (Ungaza et al., 2014) demonstraram a presença de $T$. gondii em aborto em cabras, e a confirmação do diagnóstico é necessária para o controle dos surtos.

Neste estudo, foram detectadas lesões associadas à infecção por $T$. gondii em amostras de cérebro, coração, fígado e placenta, caracterizadas por focos de infiltrado não supurativo com áreas de necrose multifocal em placentas, com áreas necróticas focais com mineralização e presença de infiltrado inflamatório mononuclear. $\mathrm{Na}$ histopatologia, as áreas branco-amareladas nos cotilédones são caracterizadas por calcificação e necrose (Dubey, 1980). Esses achados são descritos como compatíveis de infecções por protozoários e foram observados em 22 amostras de placentas examinadas em nosso estudo.

Dessas 22 amostras placentárias que apresentaram lesões na histopatologia compatíveis com $T$. gondii e que foram submetidas à IHQ, juntamente com as cinco amostras que não apresentaram lesões características. Porém, na IHQ, 23/27 apresentaram imunomarcação em epitélio das vilosidades placentárias, o que confirma a etiologia da toxoplasmose. Segundo Mota et al. (2008), a IHQ é uma técnica importante no diagnóstico da toxoplasmose, visto que os achados histopatológicos sugestivos da infecção por protozoários, inclusive Toxoplasma gondii, não são conclusivos.

Duas amostras (8,69\%) apresentaram imunomarcação no interior de vasos sanguíneos placentários, indicando presença do parasito e possível transmissão vertical. Esse achado corrobora os resultados obtidos por Atmaka et al. (2012) em cérebro e endotélio capilar em cordeiros imunopositivos para $T$. gondii $\mathrm{e}$ sinaliza infecção aguda.

Dagleish et al. (2010) identificaram, por meio da IHQ, em cotilédones, cérebro, músculos esqueléticos, cardíacos e pulmões, casos de toxoplasmose aguda em ovelhas, com marcação positiva para T. gondii. A IHQ é um método sensível, mesmo em tecido decomposto, que geralmente inviabiliza a aplicação de outras técnicas (Buxton, 1998). Além disso, a histopatologia não permite a detecção de cistos e taquizoítos de forma precisa, sendo necessários, 
portanto, testes específicos como IHQ e PCR (Van Maanen et al., 2004). Silva et al. (2013) compararam a IHQ com o MAT (teste de aglutinação modificado), e o resultado indicou que os animais que apresentaram título de 25 no MAT apresentaram imunomarcação apenas em coração para $T$. gondii. Já os animais com títulos elevados (3200) apresentaram imunodetecção em fígado, coração e cérebro. Esses autores sugerem que a IHQ deve ser utilizada no diagnóstico da toxoplasmose em tecidos, independentemente dos níveis de anticorpos no animal.

O fato de a imunomarcação ter ocorrido no epitélio das vilosidades coriônicas pode ser explicado porque, em infecções naturais, o protozoário atravessa a barreira do epitélio para ter acesso a tecidos fetais, como cérebro, placenta e retina (Barragan e Sibley, 2002).

Reações discretas na IHQ foram obtidas em $4,4 \%$ (1/23), reações moderadas em $60,8 \%$ $(14 / 23)$ e severas em $34,8 \%(8 / 23)$ das amostras de placentas analisadas na IHQ. A predominância de reações moderadas e severas pode indicar que há prejuízo causado pelo protozoário nesse órgão, conforme demonstrado por Costa et al. (2014).

Dubey et al. (2002) afirmam que as necroses focais nas vilosidades cotiledonares são decorrentes da degeneração causada pelos taquizoítos nos tecidos, sendo confirmada posteriormente na IHQ. Esta é mais sensível do que a citoquímica convencional (histopatologia) devido à identificação dos antígenos, permitindo a conclusão precisa do diagnóstico. Três animais negativos na sorologia apresentaram placentas com lesões características de $T$. gondii na histopatologia e foram positivos na IHQ, o que demonstra que esta técnica foi capaz de identificar tecido fetal infectado por $T$. gondii em cabras falso-negativas na sorologia. Tal resultado pode ter ocorrido porque as cabras estavam provavelmente na fase inicial de infecção, não havendo resposta imune materna de anticorpos detectável (toxoplasmose hiperaguda). Essa resposta, posterior à infecção oral das cabras com oocistos, geralmente é detectada após 30 dias pós-infecção como foi observado em ovelhas prenhas e não prenhas (Buxton e Finlayson et al., 1986).

Um animal positivo no ELISA e no exame histopatológico foi negativo na IHQ. Isso também pode ocorrer devido à presença do parasito em outros tecidos ou em partes do mesmo tecido não analisadas, levando a um resultado falso-negativo na IHQ (Nunes et al., 2015), o que indica a necessidade de coletar vários fragmentos dos órgãos para minimizar esse efeito.

As quatro amostras de placentas negativas na IHQ podem estar infectadas com outros patógenos distintos do $T$. gondii, visto que se trata de uma técnica segura e com sensibilidade e especificidade altas de até $100 \%$ (Navarro et al., 2009) na detecção $T$. gondii em placenta de cabras.

\section{CONCLUSÃO}

Os resultados deste estudo demonstram que a imuno-histoquímica de tecidos placentários é uma ferramenta eficaz no diagnóstico de toxoplasmose em surtos de aborto em cabras, principalmente quando associada a outras técnicas de diagnóstico, como a histopatologia e a sorologia.

\section{AGRADECIMENTOS}

À Coordenação de Aperfeiçoamento de Pessoal de Nível Superior (CAPES) pelo suporte financeiro e à Universidade Federal Rural de Pernambuco pelo apoio logístico para a realização deste estudo.

\section{REFERÊNCIAS}

ABU-DALBOUH, M.A.; ABABNEH, M.M.; GIADINIS, N.D. et al. Ovine and caprine toxoplasmosis (Toxoplasma gondii) in aborted animals in Jordanian goat and sheep flocks. Trop. Anim. Health. Prod., v.44, p.49-54, 2012.

ALVAREZ-GARCÍA, G.; COLLANTESFERNÁNDEZ, E.; COSTAS, E. et al. Influence of age and purpose for testing on the cut-off selection of serological methods in bovine neosporosis. Vet. Res., v.34, p.341-352, 2003.

ATMACA, H.T.; OCAL, N.; BABUR, C. et al. Reactivated and clinical Toxoplasma gondii infection in young lambs: clinical, serological and pathological evidences. Small Ruminant Res., v.105, p.335-340, 2012.

BARRAGAN, A.; SIBLEY, D.L. Transepithelial migration of Toxoplasma gondii is linked to parasite motility and virulence. J. Exp. Med., v.195, p.16251633, 2002. BLEWETT, D.A.; WATSON, W.A. The epidemiology of ovine toxoplasmosis. II. Possible sources of infection in outbreaks of clinical disease. Br. Vet. J., v.139, p.546-555, 1983. 
BUXTON, D. Protozoan infections (Toxoplasma gondii, Neospora caninum and Sarcocystis spp.) in sheep and goats: recent advances. Vet. Res., v.29, p.289-310, 1998.

BUXTON, D.; FINLAYSON, J. Experimental infection of pregnant sheep with Toxoplasma gondii: pathological and immunological observations on the placenta and foetus. J. Comp. Pathol., v.96, p.319333, 1986.

CALDEIRA, F.H.B.; UBIALI, D.G.; GODOY, I. et al. Outbreak of caprine abortion by Toxoplasma gondii in Midwest Brazil. Pesq. Vet. Bras., v.31, p.933-937, 2011.

CHARLESTON, W.A.G. Toxoplasma and other protozoan infections of economic importance in New Zealand. N.Z.J. Zool., v.21, p.67-81, 1994.

COSTA, R.C.; ORLANDO, D.R.; ABREU, C.C. et al. Histological and immunohistochemical characterization of the inflammatory and glial cells in the central nervous system of goat fetuses and adult male goats naturally infected with Neospora caninum. BMC Vet. Res., v.10, p.1-7, 2014.

DAGLEISH, M.P.; BENAVIDES, J.; CHIANINI, F. Immunohistochemical diagnosis of infectious diseases of sheep. Small Ruminant Res., v.92, p.19-35, 2010.

DUBEY, J.P. Persistence of encysted Toxoplasma gondii in caprine livers and public health significance of toxoplasmosis in goats. J. Am. Vet. Med. Assoc., v.177, p.1203-1207, 1980.

DUBEY, J.P. Toxoplasmosis in goats (Capra hircus). In: _. (Ed.). Toxoplasmosis of animals and humans. 2.ed. Boca Raton: CRC Press, 2010. p.137144.

DUBEY, J.P. Toxoplasmosis in sheep-the last 20 years. Vet. Parasitol., v.163, p.1-14, 2009.

DUBEY, J.P.; LEWIS, B.; BEAM, K. et al. Transplacental toxoplasmosis in a reindeer (Rangifer tarandus) fetus. Vet. Parasitol., v.110, p.131-135, 2002.

DUBEY, J.P.; LINDSAY, D.S. Neosporosis, toxoplasmosis, and sarcocystosis in ruminants. Vet. Clin. Food Anim., v.22, p.645-671, 2006.

MASSALA, G.; PORCU, R.; MADAU, L. et al. Survey of ovine and caprine toxoplasmosis by IFAT and PCR assays in Sardinia Italy. Vet. Parasitol., v.117, p.15-21, 2003.
MOELLER, R.B. Causes of caprine abortion: diagnostic assessment of 211 cases (1991-1998). J. Vet. Diagn. Invest., v.13, p.265-270, 2001.

MOTA, A.C.; VIEIRA, M.I.B.; BONDAN, C. et al. Aborto em ovinos associado à toxoplasmose: caracterização sorológica, anátomo-patológica e imunoistoquímica. Rev. Bras. Parasitol. Vet., v.17, p.204-208, 2008.

MUNDAY, B.L.; MASON, R.W. Toxoplasmosis as a cause of perinatal death in goats. Aust. Vet. J., v.55, p.485-487, 1979.

NAVARRO, J.A.; ORTEGA, N.; BUENDIA, A.J. et al. Diagnosis of placental pathogens in small ruminants by immunohistochemistry and PCR on paraffin-embedded samples. Vet. Rec., v.165, p.175178, 2009.

NUNES, A.C.B.T.; SILVA, E.M.V.; OLIVEIRA, J.A. et al. Application of different techniques to detect Toxoplasma gondii in slaughtered sheep for human consumption. Braz. J. Vet. Parasitol., v.24, p.416-421, 2015.

PEREIRA-BUENO, J.; QUINTANILLA-GOZALO, A.; PÉREZ-PÉREZ, V. et al. Evaluation of ovine abortion associated with Toxoplasma gondii in Spain by different diagnostic techniques. Vet. Parasitol., v.121, p.33-43, 2004.

PESCADOR, C.A.; OLIVEIRA, E.C.; PEDROSO, P.M.O. et al. Perdas reprodutivas associadas com infecção por Toxoplasma gondii em caprinos no sul do Brasil. Pesqui. Vet. Bras., v.27, p.167-171, 2007.

SILVA, A.F.; OLIVEIRA, F.C.R.; LEITE, B.J.S. et al. Immunohistochemical identification of Toxoplasma gondii in tissues from modified agglutination test positive sheep. Vet. Parasitol., v.191, p.347-352, 2013.

UNZAGA, J.M.; MORÉA, G.; BACIGALUPE, D. et al. Toxoplasma gondii and Neospora caninum infections in goat abortions from Argentina. Parasitol. Int., v.63, p.865-867, 2014.

VAN MAANEN, C.; WOUDA, W.; SCHARES, G. $e t$ al. An interlaboratory comparison of immunohistochemistry and PCR methods for detection of Neospora caninum in bovine foetal tissues. Vet. Parasitol., v.126, p.351-364, 2004.

WANDERLEY, F.S.; PORTO, W.J.N.; CÂMARA, D.R.C. et al. Experimental vaginal infection of goats with semen contaminated with the "CPG" strain of Toxoplasma gondii. J. Parasitol., v.99, p.610-613, 2013. 